\title{
Grußwort der Oberbürgermeisterin der Stadt Frankfurt am Main
}

\author{
Petra Roth
}

Sehr verehrte Festgäste dieser Jubiläumsveranstaltung, sehr verehrter Präsident Herr Müller-Esterl.

Herzlichen Dank für die liebenswürdigen Worte, Herr Professor Allert. In der Tat, Sie haben Recht. Ich hätte, wenn Sie das nicht erwähnt hätten, jetzt gesagt, dass Sie seit mindestens zwei Jahren mein Wort haben: Ja zu dieser Jubiläumsveranstaltung in der Frankfurter Paulskirche. Das hat auch einen Grund, dass ich damals spontan, als Herr Professor Allert mit diesem Anliegen kam, zugestimmt habe. Sie haben eben das Grußwort des hessischen Innenministers gehört. Solche „Produkte“ wie Boris Rhein und auch andere hat die Goethe-Universität ins Leben entlassen. „Produkte“ der Goethe-Universität, die dann in Frankfurt am Main arbeiten, sind für uns selbstverständlich.

Ich freue mich ganz besonders, dass Sie, Präsident a. d. Professor Steinberg da sind, der immer wieder von der starken Kraft der Goethe-Universität - da hieß sie ja noch nicht so - im ausgehenden 20., im Übergang zum 21. Jahrhundert gesprochen hat. Die geballte Kraft kommt von den Handelsinstituten, den Sozialinstituten, die hier in Frankfurt die „Keimzellen“ waren, aus denen dann die GoetheUniversität hervorgegangen ist. Ich komme noch einmal auf die hessische Landesregierung und damit auf den Minister zurück - ohne Namensnennung, weil er die Landesregierung vertritt: Das freie Denken ist bei Politikern keinesfalls selbstverständlich. Aber bei diesem Minister, in der Art wie er seine ministerielle Verantwortung wahrnimmt, wie er für seine politischen Ideen streitet, können Sie sehen: Er ist ein Kind der Goethe-Universität. Er ist ein Absolvent der Wissenschaft und der Hochschule, die von jeher eine sehr freie, die letzte im Kaiserreich gegründete Universität und eine Stiftungs- und Bürgeruniversität von Anbeginn war.

Meine Damen und Herren, die Frankfurter Paulskirche - die Wiege der Demokratie - und die Goethe-Universität prägen seit jeher das Frankfurter Bürgertum, die Frankfurter Gesellschaft und die Milieus, von denen wir ja in der Partizipationsgesellschaft sprechen, früher soziale Schichten. Es sind die Soziologen, die heute in großen Forschungsaufträgen Milieus definieren: in Ballungsräumen, in Metropolregionen, in solchen Städten wie Frankfurt am Main. Wir haben verschiedene Milieus in dieser Stadt: junge Menschen, kritische Menschen, partizipative Menschen, alte Menschen, die Zuwendung brauchen von anderen. Der Bundespräsident spricht von einer bunten Stadt. Wenn ich die Milieus farblich kennzeichne, 